\title{
Inhibitory Action of Pavetta Indica Leaf Extracts on the Corrosion of Mild Steel in Acid Media
}

\author{
V. N. SHEEJA and S. SUBHASHINI
}

Department of Chemistry, Avinashilingam Institute for Home Science and Higher Education for Women, Coimbatore-43, Tamilnadu, India

sheeja_appche2007@yahoo.co.in

Received 8 August 2013 / Accepted 30 August 2013

\begin{abstract}
The anticorrosive nature of Pavetta Indica Leaf extract (PIL) on mild steel corrosion in $\mathrm{HCl}$ and $\mathrm{H}_{2} \mathrm{SO}_{4}$ media has been studied by weight loss and electrochemical methods. The results of the study revealed that the acid extracts of PIL inhibit mild steel corrosion. The inhibition efficiency increases with increase in concentration of inhibitor. Potentiodynamic polarization studies clearly revealed that the PIL act as mixed type of inhibitor without changing the mechanism of hydrogen evolution reaction. Changes in impedance parameters are indicative of adsorption of the biomaterial on the metal surface leading to the formation of a protective layer which grows with increasing exposure time. The protective film formed on the metal surface was confirmed by SEM. Values of inhibition efficiency obtained from different methods are in good agreement and dependent upon the concentration of inhibitor.
\end{abstract}

Keywords: Corrosion inhibitiors, Mild steel, Acid media, Electrochemical impedance spectroscopy, Polarisation curves, Pavetta Indica Linn Leaf

\section{Introduction}

The working life of machinery parts will be shortened due to corrosion attack. They are sometimes accompanied by accidents. Another technical consequence of corrosion is disturbance of the machine and equipment performance, e.g., the corrosion products becoming lodged between moving parts and increasing the friction of these parts by blocking them. This may lead to different accidents, such as fires or explosions. As well, there is a possibility for food contamination due to the dissolved corrosion products or using unacceptable materials during food preparation and storages. Therefore, contamination of consumer products, e.g. food during production, storage and/or transport, due to release of chemicals caused by contact with technical components and corrosion products is of great concern. Accordingly, effective corrosion prevention and control may contribute towards the limitation of economic, social and personnel loss. All these consequences increased the pressure of society to control the corrosion attack and to save the environment. Recently the use of synthetic inhibitors has created environmental problems due to their toxic properties. 
Therefore researchers are now focusing on development of cheap, non-toxic and environmental friendly corrosion inhibitors from natural products. The natural organic inhibitors can be used as corrosion inhibitors of mild steel in acidic solution due to its active chemical activity, low toxicity and low $\operatorname{cost}^{1-4}$. As a contribution to the current interest on eco friendly, green corrosion inhibitors, the present study investigated the inhibiting effect of leaves extracts of Pavetta Indica Linn.

\section{Experimental}

Materials used for this study were CR mild steel sheet of chemical composition: C, 0.091; Mn, 0.195; Si, 0.016; P, 0.020; S, 0.013; Cr, 0.027; Mo, 0.020; Ni, 0.018; Fe, 99.6 in $\mathrm{wt} \%$. The sheet was mechanically pressed cut into $5 \mathrm{~cm} \times 1 \mathrm{~cm}$ coupons with $2 \mathrm{~mm}$ thickness, mechanically polished; a hole drilled at one end for free suspension and numbered by punching. Their edges were abraded with fine grade of emery papers, degreased with acetone, washed in double distilled water, dried, stored in a dessicator and used for the entire immersion studies. All reagents used for the study were analar grade and distilled water was used for their preparation. $1 \mathrm{M} \mathrm{HCl}$ and $1 \mathrm{M} \mathrm{H}_{2} \mathrm{SO}_{4}$ were used for gravimetric studies.

\section{About the inhibitor}

The Pavetta Indica Linn.(Rubiaceae) is a stout bushy shrub (Figure 1), found in Lanka,South China and India. The plant leaves are used in the treatment of liver diseases, Pain of pile, urinary diseases and fever ${ }^{5}$. Methanolic extracts of leaves have been reported as antipyretic and anti-inflammatory activity ${ }^{6}$. From the literature survey, it is understood that the leaves are used for making important Ayurvedic drugs without isolation of target phytochemicals. The phytochemical analysis report showed that the leaves contained macro minerals viz. Na,K,Ca and $\mathrm{Li}$ and micro elements like $\mathrm{Fe}, \mathrm{Cu}, \mathrm{Mn}, \mathrm{Zn}$ and $\mathrm{Co}$. The leaves of the plants are good source of antioxidents such as $\beta$-Carotene,Vitamin $\mathrm{C}$ and phenolics $(0.27,0.07$ and $0.25 \%)$ respectively. The leaves have been found to be rich in nutrients such as crude protein,carbohydrate and crude fiber and also vitamin $\mathrm{C}$, which is known to be a potential antioxidant ${ }^{7}$. Vitamin A and caratenoids can both accept and donate electrons and carotenoids can also quench singlet oxygen ${ }^{8}$. $\beta$-Carotene has been proved to prevent peroxidation caused by singlet oxygen and also scavenging free radicals ${ }^{9}$. Flavanoids are the major class of phenolics and have been recognized for having a potential role in the prevention of several forms of cancer and cardiovascular diseases ${ }^{10}$. The essential oil present in Pavetta Indica leaves contain 24 compounds. The major constituent of oil were $\beta$-pinene, $\beta$-eudesmol and tricyclene ${ }^{11}$. The present study therefore aims to investigate the utility of PIL extract as a anticancer remedy for mild steel cancer in acid environment.

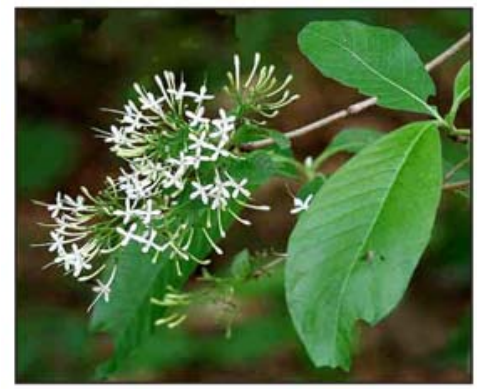

Figure 1. Pavetta Indica 


\section{Preparation of pavetta indica leaf extracts}

The leaves of plant were collected from Chalavara, a village in Palakkad, Kerala, India, cleaned and chopped into small pieces, shade dried, powdered and stored at room temperature prior to use. By using reflux extraction method, in which $25 \mathrm{~g}$ of the powder was transferred to a $1000 \mathrm{~mL}$ round bottomed flask, directly heated with $500 \mathrm{~mL}$ of $1 \mathrm{M}$ $\mathrm{HCl}$ in a mantle with water condenser at about $40-50{ }^{\circ} \mathrm{C}$ for $3 \mathrm{~h}$. The resulting solution was allowed to stand overnight and filtered through ordinary filter paper. The residue was repeatedly washed with small amount of $1 \mathrm{M} \mathrm{HCl}$ and the filtrate was made up to $500 \mathrm{~mL}$ and stored. From this 5\% stock solution of Pavetta Indica leaf extract, different concentration of inhibitor solutions ranging from 0.05 to $0.5 \%$ were diluted. The same procedure was adopted for the preparation of extract in $1 \mathrm{M} \mathrm{H}_{2} \mathrm{SO}_{4}$ also.

\section{Gravimetric measurements}

The weight loss of rectangular steel specimens of size $5 \times 1 \times 0.2 \mathrm{~cm}$ in $1 \mathrm{M} \mathrm{HCl}$ and $1 \mathrm{M}$ $\mathrm{H}_{2} \mathrm{SO}_{4}$ without and with different concentrations of PIL, was determined after $6 \mathrm{~h}$ of immersion period, at a temperature of $30{ }^{\circ} \mathrm{C}$. The extract concentration was varied from $0.05 \%$ to $0.5 \%$. After immersion the samples were dipped in bicarbonate solution, then washed with distilled water and dried. The samples were weighed before and after immersion using Shimadzu analytical balance.

\section{Electrochemical measurements}

Electrochemical experiments were carried out using Biologic Science Instruments Model SP -150 Potentiostat/Galvanostat system with EC-Lab software. A conventional three- electrode cell assembly with mild steel as a working electrode (WE), a platinum foil as a counter electrode $(\mathrm{CE})$ and standard calomel electrode $\left(\mathrm{Hg} / \mathrm{Hg}_{2} \mathrm{Cl}_{2} / \mathrm{sat}, \mathrm{KCl}\right)$ as the reference electrode(RE) was used. The working electrode was prepared from a CR steel sheet of 1x1 $\mathrm{cm}^{2}$ size which was bridge welded to a conducting rod. The immersed area other than $1 \mathrm{x} 1$ $\mathrm{cm}^{2}$ was painted and covered by polytetrafluroethylene(PTFE) tape. The specimens were polished with emery paper no. 400, cleaned with acetone ,washed with distilled water and finally dried at room temperature before being immersed in the acid solution. The electrolyte was taken into a $200 \mathrm{~mL}$ beaker with a specially designed lid, carrying three holes for maintaining the constant distance between the electrodes.

\section{The electrochemical impedance spectroscopy}

The EIS measurements were carried out at $\mathrm{E}_{\text {corr }}$ after immersion on standing in air atmosphere with the electrochemical system which include a digital potentiostat model. After the determination of steady -state current at a given potential, sine wave voltages $(-1 \mathrm{~V} ; 1 \mathrm{~V})$ peak to peak, at the frequencies between $20 \mathrm{kHz}$ to $0.1 \mathrm{~Hz}, 6$ points per decay, were superimposed on the rest potential.

\section{Polarization curves}

The working electrode was covered with PTFE other than the exposed area of $1 \mathrm{~cm}^{2}$ surface to the solution. The WE was immersed in at rest solution for 30 minutes until a steady - state open potential curve was recorded.The cathodic polarization was measured by polarizing from the $\mathrm{E}_{\text {ocp }}$ in a cathodic direction under potentiodynamic conditions corresponding to $1 \mathrm{mV} / \mathrm{s}$ using a SP1 ${ }_{50}$ model under unstirred conditions at $30^{\circ} \mathrm{C}$. After this scan, the anodic polarization curve was recorded by polarization from the $\mathrm{E}_{\mathrm{ocp}}$ in an anodic direction. 


\section{Surface analysis}

F E I Quanta FEG 200-High Resolution Scanning Electron Microscope was used for the study of the change in surface morphology of metal surface. The polished mild steel specimen wsas immersed in $1 \mathrm{M} \mathrm{HCl}$ and $1 \mathrm{M} \mathrm{H}_{2} \mathrm{SO}_{4}$ solution in the absence and presence of the optimum concentration of the green extracts for $6 \mathrm{~h}$ at room temperature. The specimen was cleaned with distilled water, dried and used for the analysis. The surface images were taken with the magnification of $2000 \mathrm{x}$ specimens.

\section{Results and Discussion}

\section{Gravimetric measurements}

Table 1 gives values of the inhibition efficiency and corrosion rates obtained from the weight loss measurements of mild steel for different concentrations of PIL in $1 \mathrm{M} \mathrm{HCl}$ and 1 $\mathrm{M} \mathrm{H}_{2} \mathrm{SO}_{4}$ at $30{ }^{\circ} \mathrm{C}$ after 6 hours of immersion.

Table 1. Corrosion rates (CR) and Inhibition efficiencies (IE) of acid extract of PIL in acid media

\begin{tabular}{ccccc}
\hline \multirow{2}{*}{$\begin{array}{c}\text { Con in } \\
\%\end{array}$} & \multicolumn{2}{c}{$1 \mathrm{M} \mathrm{HCl}$} & \multicolumn{2}{c}{$1 \mathrm{M} \mathrm{H}_{2} \mathrm{SO}_{4}$} \\
\cline { 2 - 5 } & CR in mpy & IE in \% & CR in mpy & IE \% \\
\hline 0 & 3407.97 & & 3575.11 & \\
0.05 & 610.72 & 82.08 & 767.88 & 78.52 \\
0.1 & 370.58 & 89.13 & 625.76 & 82.50 \\
0.15 & 275.76 & 91.91 & 451.14 & 87.38 \\
0.2 & 210.48 & 93.82 & 395.06 & 88.95 \\
0.25 & 203.44 & 94.03 & 369.45 & 89.67 \\
0.3 & 169.85 & 95.02 & 312.14 & 91.27 \\
0.35 & 161.59 & 95.26 & 309.19 & 91.35 \\
0.4 & 138.97 & 95.92 & 217.15 & 93.93 \\
0.45 & 72.87 & 97.86 & 185.79 & 94.80 \\
0.5 & 138.70 & 95.93 & 198.27 & 94.45 \\
\hline
\end{tabular}

The inhibition efficiency was calculated using the formula

$$
\operatorname{IE}(\%)=\left(\frac{W_{0}-W}{W_{0}}\right) x 100
$$

Were $\mathrm{W}_{0}$ and $\mathrm{W}$ are the values of weight loss of steel after immersion in solutions with out and with inhibitor respectively. The Table 1 proves the effective inhibitive action of PIL extract on mild steel corrosion. Similar trend was observed in both media as inhibition efficiency increases with the increasing inhibitor concentration up to $0.45 \%$ and slightly decreases at higher concentration. As the concentration of inhibitor increases, the rate of corrosion decreases because the inhibitor molecules prevents the dissolution of mild steel by adsorbing on the metal surface. The adsorbed molecules avoid the further contact of the acid and metal.

The performance of the inhibitor in $\mathrm{HCl}$ was found to be above $90 \%$ from $0.15 \%$ concentration onwards and the maximum inhibition efficiency was $97.86 \%$ with $0.45 \%$ concentration. In sulphuric acid the efficiency was below $90 \%$ up to $0.25 \%$ concentration and the maximum efficiency obtained was $94.8 \%$ with $0.45 \%$ concentration.

The possible mechanism for corrosion inhibition of mild steel in $\mathrm{HCl}$ and $\mathrm{H}_{2} \mathrm{SO}_{4}$ media by PIL as inhibitor may be explained on the basis of adsorption. It is assumed that chloride 
ions and sulphate ions are first adsorbed on to the metal; the adsorption of the cationic inhibitor species would be limited by the surface concentration of anions. The specific adsorption of anions having a smaller degree of hydration such as chloride ions is expected to be more pronounced. Being specifically adsorbed, they create an excess negative charge towards the solution and favor more adsorption of the cations. So a close-backed inhibitor film will form on the metal surface and inhibit dissolution of iron ions to the solution. The lesser interference by sulphate ions may lead to lower adsorption and inhibition of corrosion. This explains the higher efficiency of the plant extract in $\mathrm{HCl}$ than in $\mathrm{H}_{2} \mathrm{SO}_{4}$.

In order to obtained a better understanding of the corrosion protection mechanism of PIL against the corrosion of mild steel in $1 \mathrm{M} \mathrm{HCl}$ and $\mathrm{H}_{2} \mathrm{SO}_{4}$ medium, a detailed study on this inhibitor was carried out using Tafel polarization and EIS studies.

\section{The electrochemical impedance spectroscopy (EIS)}

Impedance is a totally complex resistance encountered when a current flows through a circuit made of resistors, capacitors or inductors, or any combination of these. The corrosion behavior of mild steel, in acidic solutions in the presence of PIL was investigated by EIS method at room temperature. The locus of the Nyquist plots was regarded as one part of a semicircle. The equivalent circuit models of Randle type employed for this system are shown below (Figure 2) which consists of parallel combination of resistor $\left(R_{2}\right)$ and capacitor $\left(\mathrm{C}_{2}\right)$, both are in series to resistor $\left(\mathrm{R}_{1}\right)$.

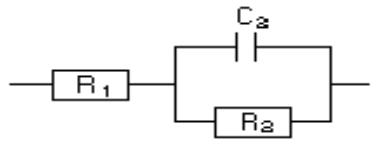

Figure 2. Electrochemical equivalent circuit for the metal/solution interface

Randle equivalent circuit was successfully applied for some corrosion and corrosion inhibition systems ${ }^{12-14}$. The Nyquist plot gives all the necessary information about the electrode-electrolyte interface and the reaction. Nyquist plots of mild steel in inhibited and uninhibited acid solutions containing various concentrations of PIL are shown in Figure 3 and 4 . The impedance diagrams obtained are not perfect semicircles, and this difference has been distributed to frequency dispersion ${ }^{15}$. The charge transfer resistance, $R_{t}$ values are calculated from the difference in impedance at lower and higher frequencies. To obtain the double layer capacitance $\left(\mathrm{C}_{\mathrm{dl}}\right)$, the frequency at which the imaginary component of the impedance is maximum (-Z"max) is found and $\mathrm{C}_{\mathrm{dl}}$ values are obtained from the equation.

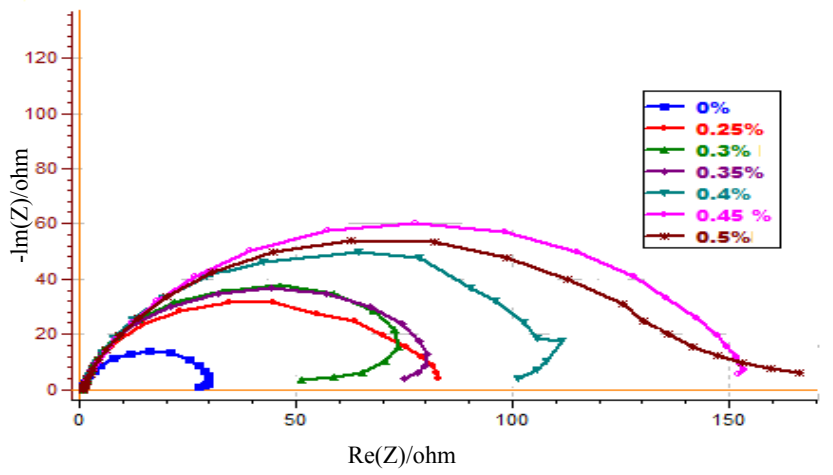

Figure 3. Nyquist diagram for mild steel in $1 \mathrm{M} \mathrm{HCl}$ containing different concentrations of PIL 


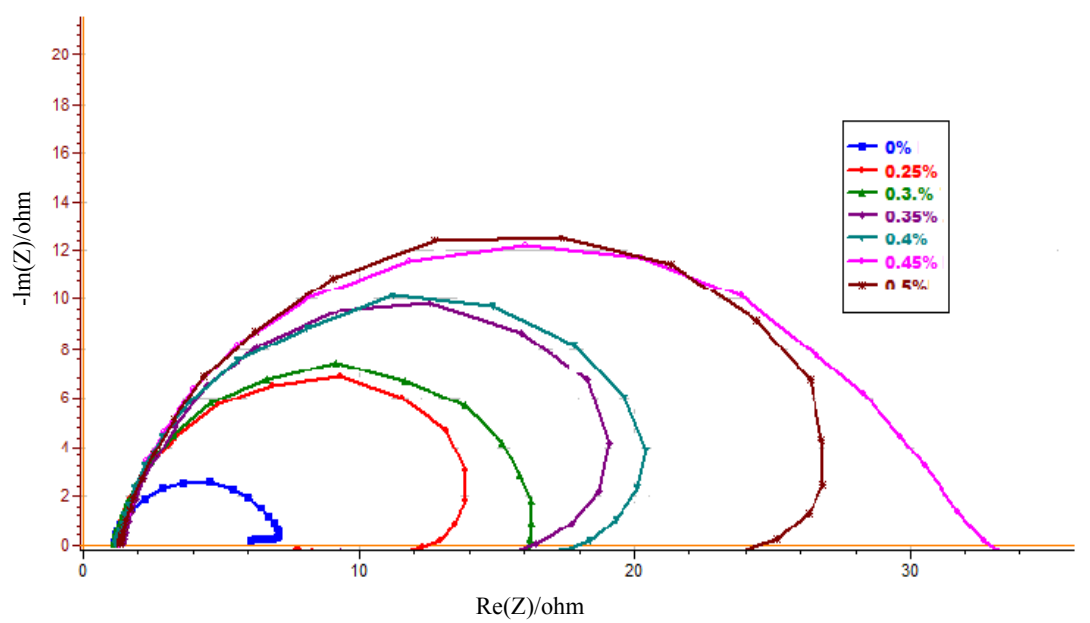

Figure 4. Nyquist diagram for mild steel in $1 \mathrm{M} \mathrm{H}_{2} \mathrm{SO}_{4}$ containing different concentrations of PIL

$$
f\left(-Z^{\prime \prime} \max \right)=\frac{1}{2 \pi C d l R t}
$$

The EIS data were displayed as Bode plots in which the logarithm of the impedance modulus $(|\mathrm{Z}|)$ was plotted versus the logarithm of the frequency (f) of the applied alternating current signal. When the frequency of an applied signal is low, $(f \rightarrow 0)$ the impedance measurements reflect the polarization resistance $\left(R_{t}\right)$, which is inversely proportional to the corrosion rate. Figure 5 and 6 shows the Bode plots of PIL in both acids.

The corrosion parameters namely charge transfer resistance $\left(\mathrm{R}_{\mathrm{t}}\right)$ and double layer capacitance $\left(\mathrm{C}_{\mathrm{dl}}\right)$ derived from Nyquist plots and the impedance, log $(\mathrm{Z} / \mathrm{ohm})$ values optained from Bode plots in both acids are given in Table 2 and Table 3.

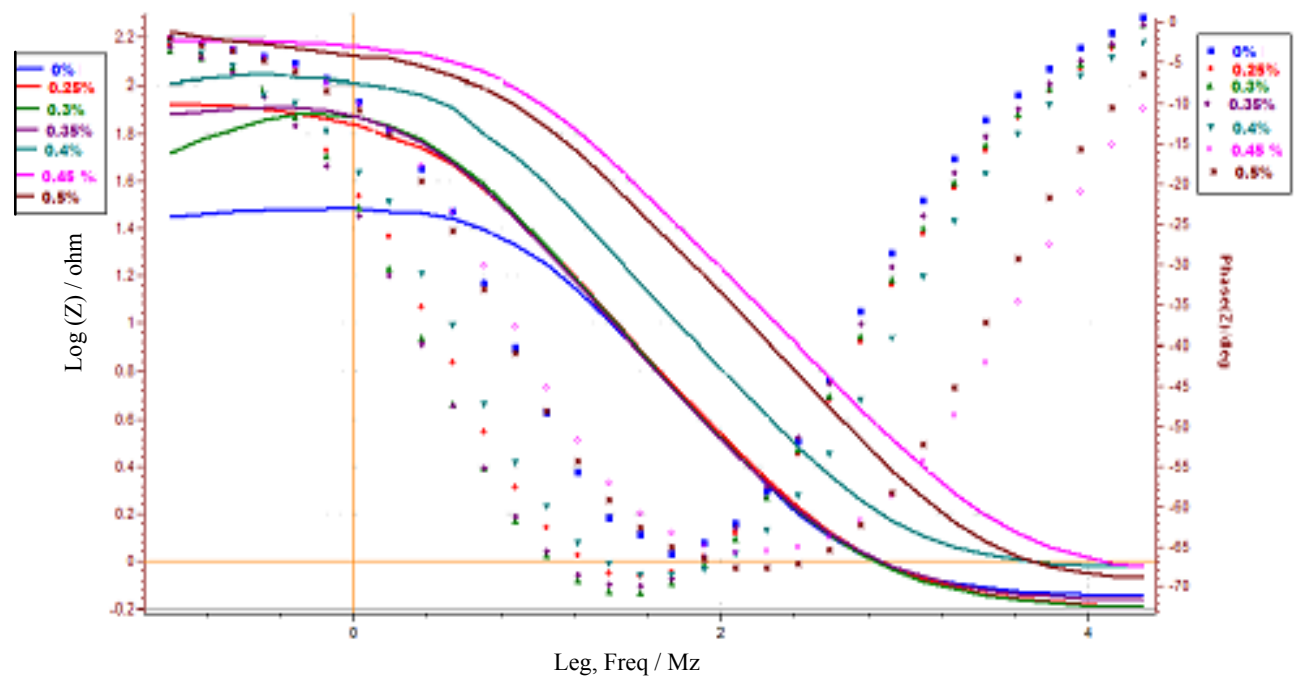

Figure 5. Bode plots for mild steel in $1 \mathrm{M} \mathrm{HCl}$ containing different concentrations of PIL 


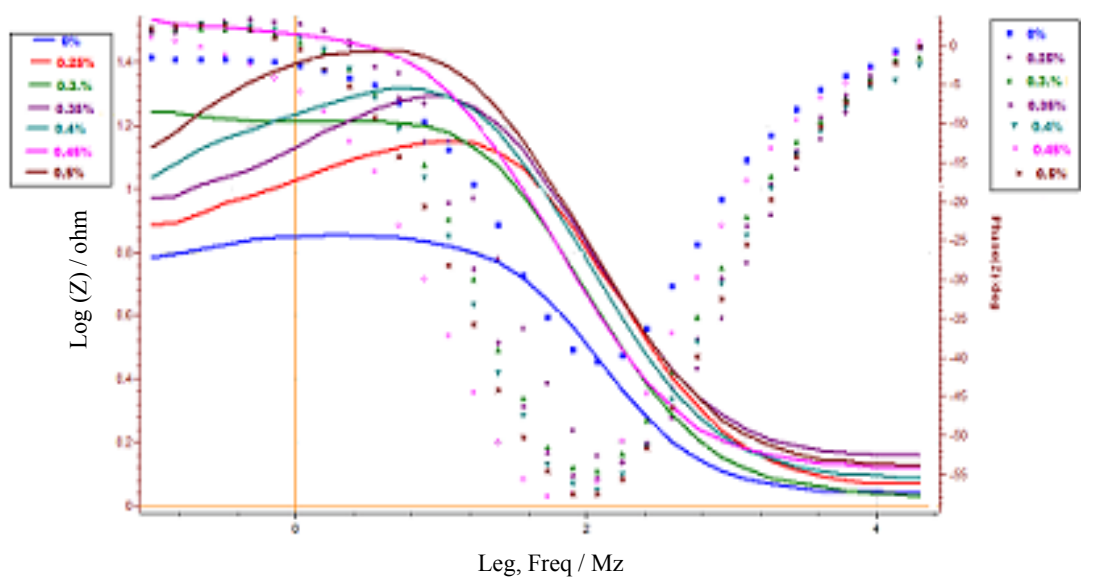

Figure 6. Bode plots for mild steel in $1 \mathrm{M} \mathrm{H}_{2} \mathrm{SO}_{4}$ containing different concentrations of PIL

Table 2. Corrosion parameters of $\mathrm{MS}$ immersed in $\mathrm{HCl}$ containing different concentrations of PIL extract obtained from Impedance spectra

\begin{tabular}{ccccc}
\hline CON & $\mathrm{R}_{\mathrm{t}}$ in Ohm $\mathrm{cm}^{2}$ & $\mathrm{C}_{\mathrm{dl}}$ in $\mu \mathrm{F}$ & IE in \% from $\mathrm{R}_{\mathrm{t}}$ & impedance $[\log (\mathrm{Z} / \mathrm{ohm}]$ \\
\hline 0 & 29.68 & 704.2 & & 1.46 \\
0.25 & 83.29 & 819.4 & 64.37 & 1.83 \\
0.3 & 84.65 & 806.2 & 64.94 & 1.86 \\
0.35 & 84.69 & 805.8 & 64.95 & 1.87 \\
0.4 & 111.4 & 412.6 & 73.36 & 2.00 \\
0.45 & 154 & 135.8 & 80.73 & 2.16 \\
0.5 & 143.8 & 145.3 & 79.36 & 2.12 \\
\hline
\end{tabular}

Table 3. Corrosion parameters of MS immersed in $\mathrm{H}_{2} \mathrm{SO}_{4}$ containing different concentrations of PIL extract obtained from Impedance spectra

\begin{tabular}{ccccc}
\hline CON & $\mathrm{R}_{\mathrm{t}}$ in $\mathrm{Ohm} \mathrm{cm}^{2}$ & $\mathrm{C}_{\mathrm{dl}}$ in $\mu \mathrm{F}$ & IE in \% from $\mathrm{R}_{\mathrm{t}}$ & Impedance $[\log (\mathrm{Z} / \mathrm{ohm}]$ \\
\hline 0 & 5.897 & 734.4 & & 0.87 \\
0.25 & 13.33 & 324.9 & 55.76 & 1.03 \\
0.3 & 15.29 & 419.9 & 61.43 & 1.22 \\
0.35 & 19.07 & 336.8 & 69.08 & 1.14 \\
0.4 & 21.24 & 302.3 & 72.24 & 1.24 \\
0.45 & 30.11 & 469.6 & 80.42 & 1.49 \\
0.5 & 27.21 & 350.3 & 78.33 & 1.40 \\
\hline
\end{tabular}

It is observed that when mild steel immersed in hydrochloric acid solution containing PIL extract, the $R_{t}$ value is $29.68 \mathrm{ohm} \mathrm{cm}{ }^{2}$. The $C_{d l}$ value is $704.2 \mu \mathrm{F}$. The impedance value $\left[\log (\mathrm{Z} / \mathrm{ohm}]\right.$ is 1.46 . When $0.45 \%$ of the inhibitor is added the $\mathrm{R}_{\mathrm{t}}$ value increases from 29.68 to $154 \mathrm{ohm} \mathrm{\textrm {cm } ^ { 2 }}$. The $\mathrm{C}_{\mathrm{dl}}$ value decreases from $704.2 \mu \mathrm{F}$ to $135.8 \mu \mathrm{F}$. The impedance value $^{16,17}$ increases from 1.46 to 2.16 . This observation suggests that protective film is formed on the metal surface ${ }^{18-27}$.

From Table 3 it is observed that in sulphuric acid medium, the $\mathrm{R}_{\mathrm{t}}$ value is increased

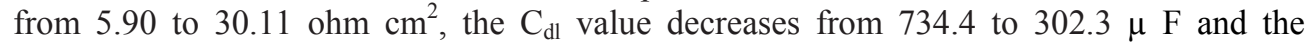
impedance value from 0.87 to1.49. The efficiency in $1 \mathrm{M} \mathrm{H}_{2} \mathrm{SO}_{4}$ is comparatively lower than that in $1 \mathrm{M} \mathrm{HCl}$ solution. 
The inhibition efficiency of corrosion of steel is calculated from charge transfer resistance as follows

$$
\eta \%=\frac{R_{\text {tblank }}^{-1}-R_{t}(\mathrm{inh})^{-1}}{R_{\text {tblank }}^{-1}} \times 100
$$

Where $\mathrm{R}_{\text {tblank }}$ and $\mathrm{R}_{\mathrm{t}(\mathrm{inh})}$ are the charge transfer resistance values without and with inhibitor, respectively. The general shape of the impedance spectra, which in this case corresponds to a parallel combination of the electrode capacitance ${ }^{28}$, did not differ in the presence of the different concentrations of inhibitor. This indicates that although the corrosion rates changed, the corrosion mechanism remained the same.

\section{Effect of immersion time}

Electrochemical impedance spectroscopy is a useful technique for long time tests, because they do not significantly disturb the system and it is possible to follow it overtime ${ }^{29}$. Immersion time experiments in the present work were carried out in $\left(1 \mathrm{M} \mathrm{HCl} / \mathrm{H}_{2} \mathrm{SO}_{4}+0.45 \% \mathrm{PIL}\right)$ solution for $360 \mathrm{~min}$ and Nyquist plots were recorded for every $60 \mathrm{~min}$. The results obtained showed that the immersion time has a significant influence on the size and shape of the impedance spectra and it effects the inhibition efficiency of PIL also. Deviations from a perfect circular shape indicate frequency dispersion of interfacial impedance. This anomalous phenomenon is attributed in the literature to the non homogeneity of the electrode surface arising from the surface roughness or interfacial phenomena ${ }^{30,31}$. The Nyquist diagram can be represented in Figure 7 and 8 at optimum concentration of inhibitor in (i) $\mathrm{HCl}$ and (ii) $\mathrm{H}_{2} \mathrm{SO}_{4}$.

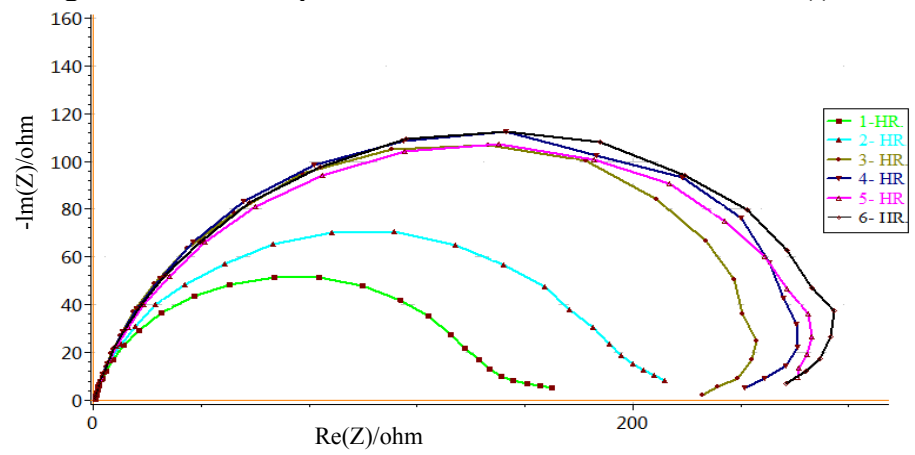

Figure 7. Nyquist diagram for mild steel in $1 \mathrm{M} \mathrm{HCl}$ at different time interval in optimum concentrations of PIL

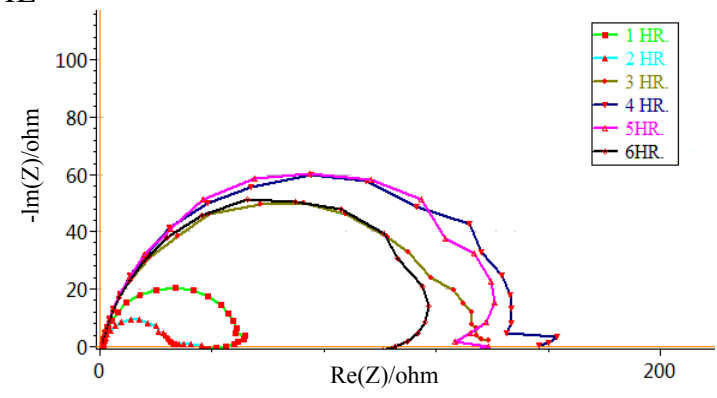

Figure 8. Nyquist diagram for mild steel in $1 \mathrm{M} \mathrm{H}_{2} \mathrm{SO}_{4}$ at different time interval in optimum concentrations of PIL 
The relationship between $\mathrm{R}_{t}$ and $\mathrm{C}_{\mathrm{d}} \mathrm{l}$ values and immersion time in $\mathrm{HCl}$ medium is shown in Figure 9 and 10. It is found that the $\mathrm{R}_{t}$ values for mild steel in $1 \mathrm{M} \mathrm{HCl}$ without PIL decreases with the immersion time, whereas the $R_{t}$ values for steel in $1 \mathrm{M} \mathrm{HCl}$ with inhibitor increases with immersion time (Figure 9). At the same time, the $C_{d l}$ values in blank solution (Figure 10) increases along with the immersion time. The change in $R_{t}$ and $C_{d} l$ values is due to the gradual replacement of water molecules by the anions of the acid and by the adsorption of the organic molecules on the metal surface, decreasing the extent of dissolution reaction ${ }^{32}$.

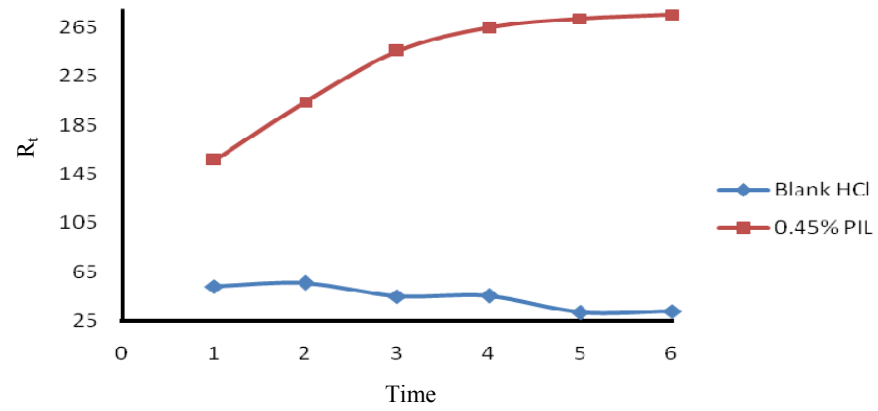

Figure 9. Relation between $\mathrm{R}_{\mathrm{t}}$ and immersion time for mild steel without and with $0.45 \%$ PIL in $1 \mathrm{M} \mathrm{HCl}$

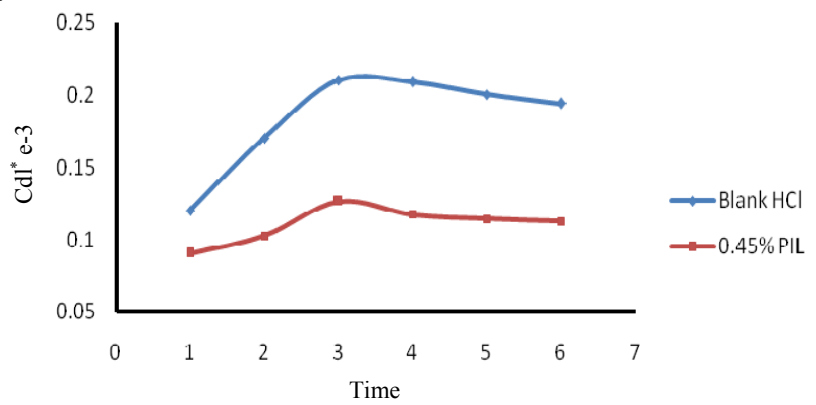

Figure 10. Relation between $\mathrm{C}_{\mathrm{dl}}$ and immersion time for mild steel without and with $0.45 \%$ PIL in $1 \mathrm{M} \mathrm{HCl}$

Figure11 and 12 shows the relationship between $\mathrm{R}_{\mathrm{t}}$ and $\mathrm{C}_{\mathrm{dl}}$ values in $\mathrm{H}_{2} \mathrm{SO}_{4}$ medium and the immersion time, Which also have the same trend as in $\mathrm{HCl}$ solution.

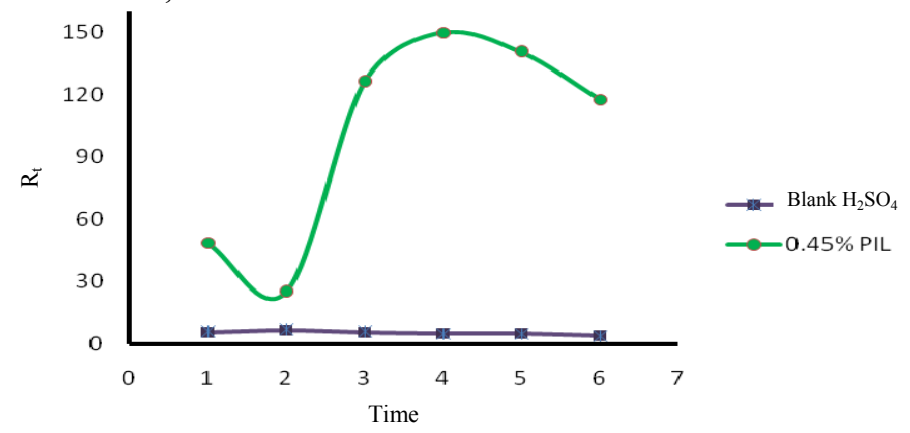

Figure 11. Relation between $\mathrm{R}_{\mathrm{t}}$ and immersion time for mild steel in $1 \mathrm{M} \mathrm{H}_{2} \mathrm{SO}_{4}$ and $0.45 \%$ of PIL extract 


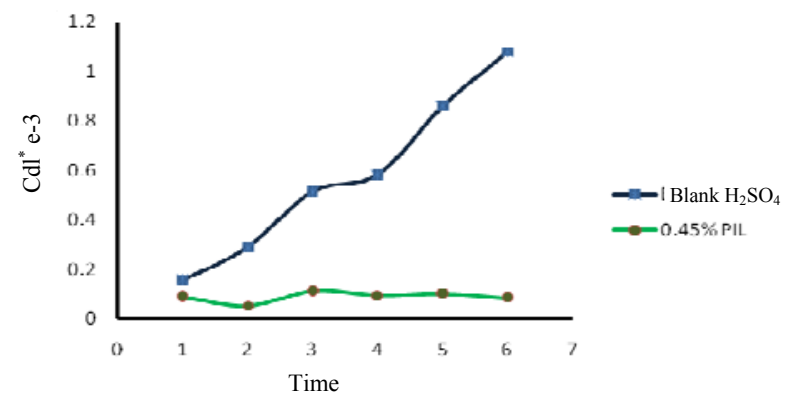

Figure 12. Relation between $\mathrm{C}_{\mathrm{dl}}$ and immersion time for mild steel in $1 \mathrm{M} \mathrm{H}_{2} \mathrm{SO}_{4}$ and $0.45 \%$ of PIL extract

\section{Polarisation curves}

Anodic and cathodic polarisation curves for mild steel in both acids at various concentrations of PIL are shown in Figure 13 and 14. It is clear the cathodic reaction (hydrogen evolution) is inhibited and the inhibition increased along with the inhibitor concentration. Tafel lines of nearly equal slopes were obtained.

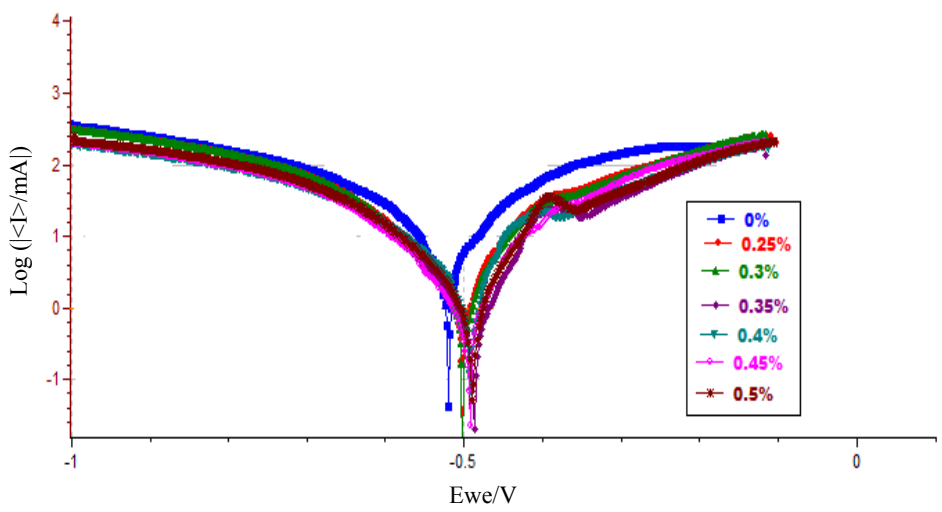

Figure 13. Potentiodynamic polarization curves for mild steel in $1 \mathrm{M} \mathrm{HCl}$ containing different concentrations of PIL

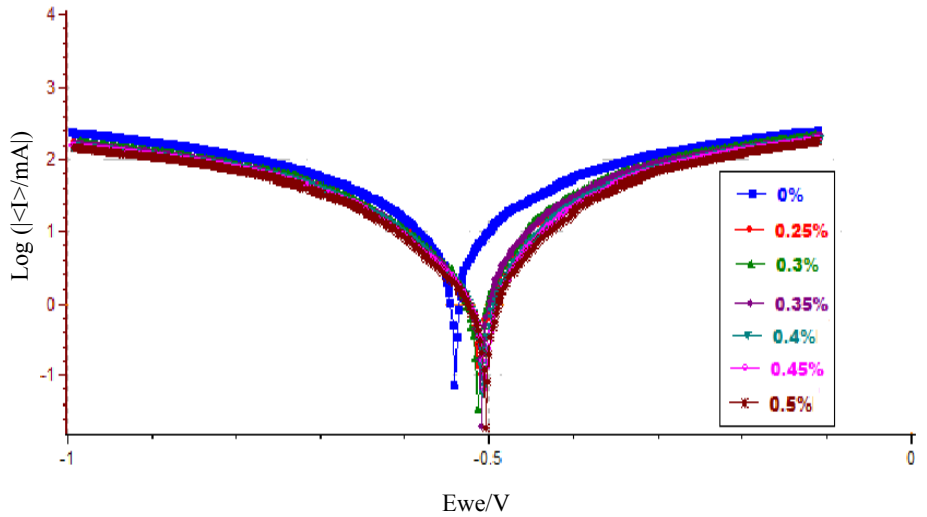

Figure 14. Potentiodynamic polarization curves for mild steel in $1 \mathrm{M} \mathrm{H}_{2} \mathrm{SO}_{4}$ containing different concentrations of PIL 
The constancy of this cathodic slope can indicate that the mechanism of proton discharge reaction does not change by addition of the inhibitor to the acid media. Values of corrosion current density $\left(\mathrm{I}_{\text {corr }}\right)$, corrosion potential $\left(\mathrm{E}_{\mathrm{corr}}\right)$, cathodic Tafel slope $\left(\mathrm{b}_{\mathrm{c}}\right)$, anodic Tafel slope $\left(b_{a}\right)$ and corrosion inhibition efficiency $(\eta \%$ for different concentrations of PIL in both acids are given in Table 4 and 5. The inhibition efficiency is defined as

$$
\eta \%=\frac{I_{\text {corr }}-I_{\text {corr }(i n h)}}{I_{\text {corr }}} \times 100
$$

Table 4. Potentiodynamic polarization parameters for the corrosion of mild steel in $1 \mathrm{M} \mathrm{HCl}$ containing different concentrations of PIL

\begin{tabular}{ccccccccc}
\hline $\begin{array}{c}\mathrm{CON} \\
\text { in } \%\end{array}$ & $\begin{array}{c}\mathrm{E}_{\text {corr }} \\
\text { in } \mathrm{mV}\end{array}$ & $\begin{array}{c}\mathrm{I}_{\text {corr }} \text { in } \\
\mu \mathrm{Acm}^{-2}\end{array}$ & $\begin{array}{c}\text { beta c } \\
\text { in } \mathrm{mV}\end{array}$ & $\begin{array}{c}\text { beta a } \\
\text { in } \mathrm{mV}\end{array}$ & $\begin{array}{c}\mathrm{CR} \text { in } \\
\mathrm{mpy}\end{array}$ & $\begin{array}{c}\mathrm{R}_{\mathrm{p}} \text { in } \\
\mathrm{Ohm} \mathrm{\textrm {cm } ^ { 2 }}\end{array}$ & $\begin{array}{c}\mathrm{IE} \% \text { from } \\
\mathrm{I}_{\text {corr }}\end{array}$ & $\begin{array}{c}\mathrm{IE} \% \\
\text { from } \mathrm{R}_{\mathrm{p}}\end{array}$ \\
\hline 0 & -518.12 & 4448.81 & 115.40 & 97.30 & 2030.91 & 2.31 & & \\
0.25 & -499.26 & 2071.02 & 118.60 & 86.90 & 945.43 & 3.50 & 53.45 & 34.00 \\
0.3 & -502.61 & 1814.37 & 112.50 & 91.00 & 828.27 & 3.43 & 59.22 & 32.65 \\
0.35 & -493.01 & 1685.94 & 117.90 & 72.30 & 769.64 & 5.39 & 62.10 & 57.14 \\
0.4 & -489.86 & 1526.12 & 118.30 & 84.10 & 696.68 & 5.61 & 65.70 & 58.82 \\
0.45 & -486.01 & 1116.80 & 115.10 & 81.60 & 509.83 & 5.26 & 74.90 & 56.08 \\
0.5 & -489.47 & 1184.41 & 119.40 & 78.90 & 540.69 & 5.59 & 73.38 & 58.68 \\
\hline
\end{tabular}

Table 5. Potentiodynamic polarization parameters for the corrosion of mild steel in $1 \mathrm{M}$ $\mathrm{H}_{2} \mathrm{SO}_{4}$ containing different concentrations of PIL

\begin{tabular}{ccccccccc}
\hline Con & $\begin{array}{c}\mathrm{E}_{\text {corr }} \text { in } \\
\mathrm{mV}\end{array}$ & $\begin{array}{c}\mathrm{I}_{\text {corr }} \text { in } \\
\mu \mathrm{Acm}\end{array}$ & $\begin{array}{c}\text { beta c } \\
\text { in } \mathrm{mV}\end{array}$ & $\begin{array}{c}\text { beta a } \\
\text { in } \mathrm{mV}\end{array}$ & $\begin{array}{c}\mathrm{CR} \text { in } \\
\mathrm{mpy}\end{array}$ & $\begin{array}{c}\mathrm{R}_{\mathrm{p}} \text { in } \\
\text { Ohmcm }^{2}\end{array}$ & $\begin{array}{c}\mathrm{IE} \% \\
\text { from } \mathrm{I}_{\text {corr }}\end{array}$ & $\begin{array}{c}\mathrm{IE \%} \\
\text { from } \mathrm{R}_{\mathrm{p}}\end{array}$ \\
\hline 0 & -539.84 & 3956.75 & 120.10 & 110.60 & 1806.28 & 2.97 & & \\
0.25 & -511.36 & 1692.97 & 121.50 & 87.10 & 772.85 & 5.19 & 57.21 & 42.77 \\
0.3 & -513.43 & 1565.09 & 119.60 & 85.10 & 714.47 & 3.97 & 60.45 & 25.19 \\
0.35 & -512.34 & 1499.88 & 119.50 & 81.60 & 684.71 & 4.80 & 62.09 & 38.13 \\
0.4 & -507.93 & 1257.52 & 115.20 & 85.50 & 574.07 & 5.57 & 68.22 & 46.68 \\
0.45 & -505.05 & 1073.78 & 117.90 & 85.50 & 490.19 & 6.23 & 72.86 & 52.33 \\
0.5 & -504.70 & 1136.08 & 116.50 & 83.30 & 518.63 & 6.13 & 71.29 & 51.55 \\
\hline
\end{tabular}

Where $I_{\text {corr }}$ and $I_{\text {corr(inh) }}$ are the corrosion current density values without and with inhibitor, respectively, determined by extrapolation of cathodic Tafel lines to the corrosion potential. The polarization resistances $(R \mathrm{p})$ were calculated from the linear $I v s E$ plots in the potential range $\pm 25 \mathrm{mV}$ from the corrosion potential. Inhibition efficiency calculated using the following equation.

$$
\eta \%=\frac{R_{p(i n h)}-R_{p}}{R_{p(i n h)}} x 100
$$

Where $R_{p}$ and $R_{p(i n h)}$ are the polarization resistance values without and with inhibitor.

From this result, it can be concluded that:

- The values of corrosion current density $\left(\mathrm{I}_{\text {corr }}\right)$ of mild steel in the inhibited solution were smaller than those for the inhibitor - free solution,

- $\mathrm{I}_{\text {corr }}$ decreases with increasing inhibitor concentration .

- Addition of PIL does not change the value of bc in both acids which clearly indicated the influence of PIL on the kinetics of hydrogen evolution reaction. 
- The anodic (ba) and cathodic (bc) Tafel slopes do not change significantly in inhibited solution as compared to uninhibited solution. This observation suggest that PIL adsorb on the metal surface by blocking the active sites of steel surface without effecting the mechanism of corrosion. This type of behavior has been observed for mild steel in acid solutions containing PIL $^{33}$

- It has been reported ${ }^{34}$, if the displacement in $E_{\text {corr }}$ is over than $85 \mathrm{mV}$ the inhibitor can be seen as a cathodic or anodic type inhibitor and if the displacement of $E_{\text {corr }}$ is lower than $85 \mathrm{mV}$, the inhibitor can be seen as mixed type. In the present investigation, the maximum deviation range is less than $85 \mathrm{mV}$ which reveals that PIL extract acts as mixed type of inhibitor.

- The increasing linear polarization ( $\mathrm{Rp}$ ) values also confirm the corrosion inhibitive nature of the plant extract.

- The inhibition efficiency calculated from $\mathrm{R}_{\mathrm{p}}$ and $\mathrm{I}_{\text {corr }}$ had the same trend in both media but IE $\%$ from $R_{p}$ value is lesser than $I_{\text {corr }}$ value.

- The results obtained from the polarization curves correspond to those from the corrosion weight loss and electrochemical impedance spectroscopy tests.

\section{Comparison of results of electrochemical studies and non electrochemical studies}

It can be clearly seen that all different techniques show that the corrosion inhibition efficiency increases with the increase of inhibitor concentration, reaching a maximum value at $0.45 \%$ of inhibitor (Figure 15). The discrepancy in the IE values obtained from different techniques can be interpreted as the result of different measurements time. The difference observed can be attributed to the difference in measurement methods and to the fact that the chemical methods give average corrosion rates, where as electrochemical methods gives instantaneous corrosion rates ${ }^{35}$.

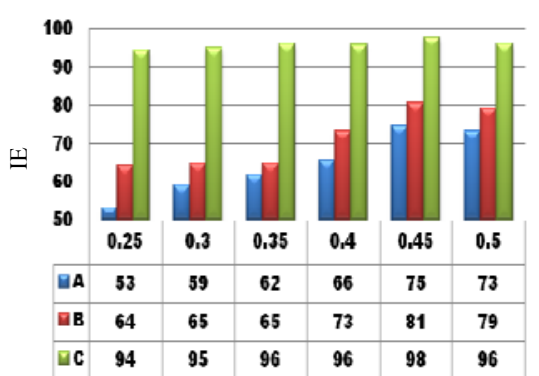

(i)

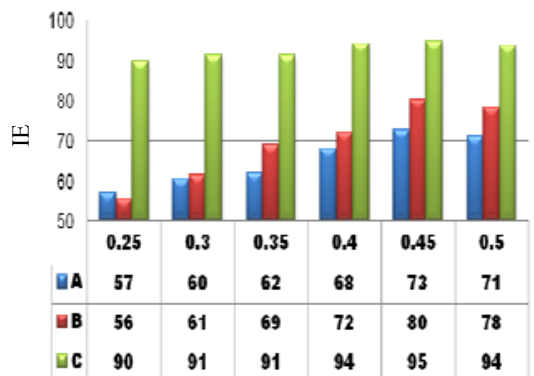

(ii)

Figure 15. Inhibition efficiency for mild steel in (i) $1 \mathrm{M} \mathrm{HCl}$ and (ii) $\mathrm{H}_{2} \mathrm{SO}_{4}$ containing different concentrations of PIL (A) polarization curves (B)charge transfer resistance and (C) weight loss measurements.

\section{Mechanism of inhibition}

The transition of metal/solution interface from a state of active dissolution to the passive state is attributed to the adsorption of the inhibitor molecules at the metal/solution interface, forming a protective film ${ }^{36}$. Adsorption process can occur through the replacement of solvent molecules from metal surface by ions and molecules accumulated in the vicinity of metal/solution interface. Ions can accumulate at the metal/solution interface in excess of those required to balance the charge on the metal at the operating potential. These ions replace solvent molecules from the metal surface and their centers reside at the inner helmholtz plane. 
This phenomenon is termed specific adsorption or contact adsorption. The leaves of the PIL contain $12.87 \%$ crude protein and $39.94 \%$ crude fiber $^{7}$. The fibers and proteins are hydrolyzed during the extract preparation releasing number of amino acids. This amino acid contains nitrogen, oxygen atoms and aromatic and heterocyclic rings. In aqueous acidic solutions, the constituents exist either as neutral molecules or as protonated molecules (cations). The inhibitors may adsorb on the metal/acid solution interface by one and/or more of the following ways:

(i) Electrostatic interaction of protonated molecules with already adsorbed chloride/ sulphate ions,

(ii) Donor-acceptor interactions between the $\pi$-electrons of aromatic ring and vacant $\mathrm{d}$ orbital of surface iron atoms,

(iii) Interaction between unshared electron pairs of hetero atoms and vacant d-orbital of iron surface atoms.

Since chloride ions/sulphate ions have a smaller degree of hydration, thus they could bring excess negative charges in the vicinity of the interface and favors more adsorption of the positively charged inhibitor molecules, the protonated inhibitors adsorb through electrostatic interactions between the positively charged molecules and the negatively charged metal surface. Thus there is a synergism between adsorbed $\mathrm{Cl}^{-}$ions /sulphate ions and protonated inhibitors. Therefore inhibition of mild steel corrosion in $1 \mathrm{M} \mathrm{HCl}$ and $1 \mathrm{M}$ $\mathrm{H}_{2} \mathrm{SO}_{4}$ is due to the adsorption of extract constituents on the mild steel surface.

\section{Surface analysis}

The corrosion prevention ability of the plant extract was strongly supported by the images recorded by scanning electron microscopic techniques. The photographs of different metal surfaces are given in Figure 16 (a-e) On comparing these micrographs, the specimen immersed in the inhibitor solutions (c and e) has apparently smooth surface when compared with that of corroded rough and uneven surface of mild steel immersed in $\mathrm{HCl} / \mathrm{H}_{2} \mathrm{SO}_{4}$ alone $(b$ and d). This is due to the adsorption of inhibitor molecules on the metal surface forming a protective layer $^{37}$. SEM provides a two-dimensional projection or a two-dimensional image of a sample.
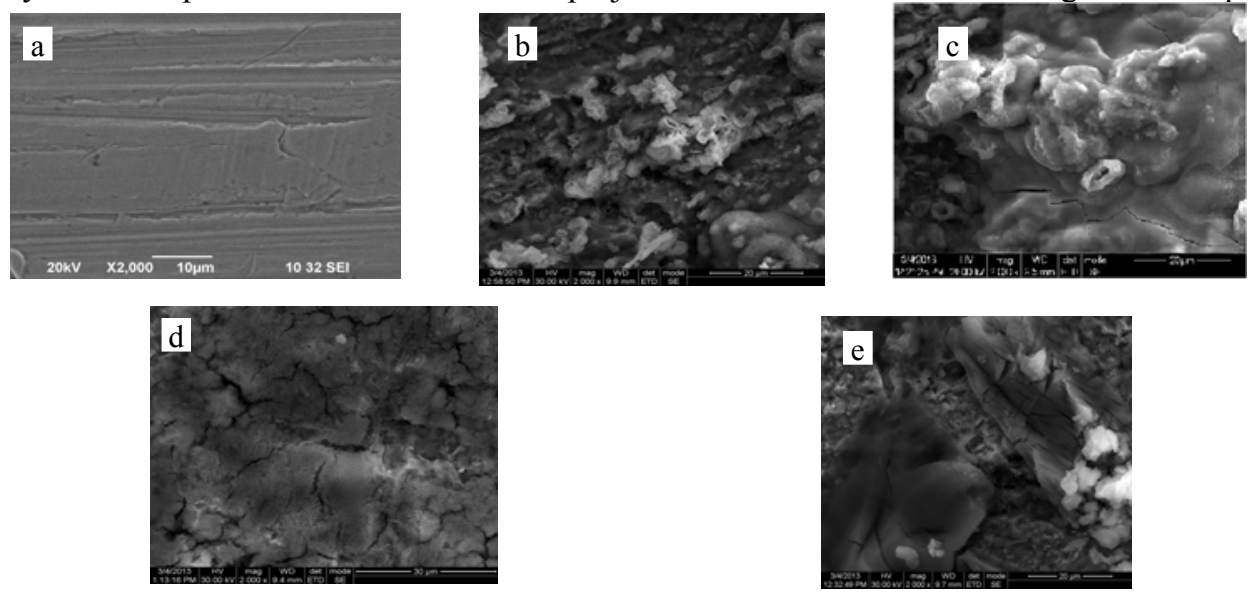

Figure 16. SEM photograph of the surface for polished: (a) Mild steel; (b) Mild steel exposed to $1 \mathrm{M} \mathrm{HCl}$ only; (c) Mild Steel sample exposed to $1 \mathrm{M} \mathrm{HCl}$ having $0.45 \%$ PIL; (d) Mild steel exposed to $1 \mathrm{M} \mathrm{H}_{2} \mathrm{SO}_{4}$; (e) Mild Steel sample exposed to $1 \mathrm{M} \mathrm{H}_{2} \mathrm{SO}_{4}$ having $0.45 \%$ PIL 


\section{Conclusion}

On the basis of the experimental results obtained in the present study, the following conclusions can be drawn:

1. PIL acts as an inhibitor for mild steel corrosion in both $\mathrm{HCl}$ and $\mathrm{H}_{2} \mathrm{SO}_{4}$ medium, but better the performance was seen in the case of $\mathrm{HCl}$ medium.

2. At $0.45 \%$ of concentration, the inhibitor showed higher inhibition efficiency in both acid medium.

3. PIL acts as a mixed inhibitor in both acid solutions.

4. SEM micrographs revealed the presence of a protective layer over the mild steel surface by the inhibitors through an adsorption process.

5. The weight loss, electrochemical impedance spectroscopy and polarization curves were in good agreement.

\section{References}

1. Li W, He Q, Pei C and Hou B, Electrochim Acta, 2007, 52(22), 6386-6394; DOI:10.1016/j.electacta.2007.04.077

2. Li W, Zhao X, Liu F and Hou B, Corros Sci., 2008, 50(11), 3261-3266; DOI:10.1016/j.corsci.2008.08.015

3. Ramesh S, Rajeswari S and Maruthamuthu S, Mater Lett., 2003, 57(29), 4547-4554; DOI:10.1016/S0167-577X(03)00360-4.

4. Stupnisek-Lisac E, Sorić T and Podbrscek S, J Appl Electrochem.,1994, 24(8), 779784; DOI:10.1007/BF00578094

5. Kritika K R and Basu B D, Indian Medicinal Plants, 1933, 3, Basu L M, Allahabad, India, 1786-1789.

6. Mandal S C, Mohanalakshmi S, Ashok Kumar C K, Surand T K and Boominathan R, Phytother Res., 2003, 17(7), 817-820; DOI:10.1002/ptr.1095

7. $\quad$ Prasad K and Bisht G, Res J Phytochem., 2011, 5(1), 54-59.

8. Devi V K and Rehman F, An Overview Indian J Phrm Educ., 2002, 36(1), 3-8.

9. Meydani S N, Meydani M,Verdan C P, Shapiro A A, Blumberg J B and Hayes K C, Mech Aging Dev., 1986, 34(2), 191-201;

DOI:10.1016/0047-6374(86)90034-5

10. Shetgiri P P and D'Mello P M, Indian Drugs, 2003, 40, 567-569.

11. Prasad K, Moulekhi K and Bisht G, Research J Phytochem., 2011,5(1), 66-69.

12. Zho P, Liang Q C and Li Y, Appl Surf Sci., 2005, 252(5), 1596-1607;

DOI:10.1016/j.apsusc.2005.02.121

13. Dehri I and Ozcan, Mater Chem Phys., 2006, 98(2-3), 316-323;

DOI:10.1016/j.matchemphys.2005.09.020

14. Khaled K F, Appl Surf Sci., 2006, 252(12), 4120-4128;

DOI:10.1016/j.apsusc.2005.06.016

15. Mansfeld F, Kending M W andTsai S, Corrosion, 1981, 37, 301, Ibid., 38, 570.

16. Pandiarajan M, Prabhakar P and Rajendran S, Chem Sci Trans., 2013, 2(2), 605-613; DOI:10.7598/cst2013.395

17. Sribharathy V, Susai Rajendran and Sathiyabama J, Chem Sci Trans., 2013, 2(1), 315-321; DOI:10.7598/cst2013.252

18. Shyamaladevi B and Rajendran S. Eur Chem Bull., 2012, 1(2), 503-510.

19. Kalaivani R, Narayanaswamy B, Selvi J A, Amalraj A J, Jeyasundari J and Rajendran S, Portugaliae Electrochemica Acta, 2009, 27(2), 177-187. 
20. Anthony Samy Sahayaraja and Susai Rajendran, J Electrochem Sci Eng., 2012, 2, 91-104.

21. Manimaran N, Rajendran S, Manivannan M and Johnmary S, Res J Chem Sci., 2012, 2(3), 52-57.

22. Sribharathy V and Susai Rajendran S, Res J Chem Sci., 2012, 2(6), 72-81.

23. Mary Anbarasi C, Susai Rajendran, Vijaya N, Manivannan M and Shanthi T, Open Corros J., 2011, 4, 40-46.

24. Johnsirani V, Rajendran S, Sathiyabama J, Muthumegala T S, Krishnaveni A and Hajarabeevi N, Bulgarian Chem Commu., 2012, 44(1), 41-51.

25. Sangeetha M, Rajendran S, Sathiyabama J, Krishnaveni A, Shanthy P, Manimaran N and Shyamaladevi B, Portugaliae Electrochimica Acta, 2011, 29(6), 429-444.

26. Rajendran S, Uma V, Krishnaveni A, Jeyasundari J, Shyamaladevi B and Manivannan M, Arabian J Sci Eng., 2009, 34(2C), 149-158.

27. Noreen Antony, Benita Sherine H and Susai Rajendran, Portugaliae Electrochimica Acta, 2010, 28(1), 1-14.

28. Mansfeld F and Lorenz W J, Electrochemical impedance spectroscopy (EIS): application in corrosion science and technology, In Varma R and Selman J R (Ed.), Techniques for Characterization of Electrodes and Electrochemical Processes. Wiley, New York, N.Y, 1991, 581-647.

29. Moretti G, Guidi F and Grion G, Corros Sci., 2004, 46, 387-403.

30. Prabhu R A, Shanbhag A V and Venkatesha T V, J Appl Electrochem., 2007, 37(4), 491-497; DOI:10.1007/s10800-006-9280-2

31. Anand R R, Hurd R M and Hackerman N, J Electrochem Soc., 1965, 112(2), 138-144.

32. Bentiss F, Traisnel M and Lagrenee M, Corros Sci., 2000, 42(1), 127-146.

33. Arab S T, Al-Turkustani A M and Al-Nami S Y, Mater Sci Res Ind., 2005, 3(2), 99-110.

34. Satapathy A K, Gunasekaran G, Sahoo S C, Amit K and Rodrigues P V, Corros Sci., 2009, 51(12), 2848-2856; DOI:10.1016/j.corsci.2009.08.016

35. Muralidharan S, Babu B R, Rengamani S and Iyer S V, J Appl Electrochem., 1996, 26(3), 291-296; DOI:10.1007/BF00242098

36. Ritchie I M, Bailey S and Woods R, Adv Colloid Interface Sci., 1999, 80(3), 183-231; DOI:10.1016/S0001-8686(98)00082-7

37. Prabhu R A, Venkatesha T V and Shanbhag AV, J Iran Chem Soc., 2009, 6(2), 353363; DOI:10.1007/BF03245845 